\title{
Lowering solid oxide fuel cell (SOFC) operating temperature by using nanocomposite ceria carbonate electrolytes
}

\author{
Ieeba khan* and Suddhasatwa Basu
}

Department of Chemical Engineering, Indian Institute of Technology Delhi, New Delhi-110016, India

Email:* ieebakhan@chemical.iitd.ac.in,\# sbasu@iitd.ac.in

Solid oxide fuel cells (SOFCs) are the electrochemical devices that convert chemical energy into the electrical energy as shown in the Figure 1. SOFCs are the clean and efficient sources of energy, having a combined heat and power efficiency of more than $80 \%$. Conventional SOFCs use yttria stabilized zirconia (YSZ) as the electrolyte material. Main issue with the conventional SOFCs using YSZ as the electrolyte material is the high operating temperature (around $1000^{\circ} \mathrm{C}$ ) to obtain sufficient ionic conductivity $\left(0.1 \mathrm{~S} \mathrm{~cm} \mathrm{~cm}^{-1}\right)$. High temperature of operation creates problems for material selection and compatibility issues of various cell components, hence all over the world research is going on to lower the operating temperature of the SOFC[1]. On lowering the operating temperature the Ohmic resistance (mainly due to the electrolyte) increases, therefore the solution to this increase in the resistance is either choosing a new material ( e.g. doped ceria ) or by making fuel cells with very thin electrolytes using new techniques like screen printing, sputtering, plasma vapor deposition etc. The latter involves greater manufacturing costs. Doped ceria has a conductivity of $0.1 \mathrm{~S} \mathrm{~cm}^{-1}$ at $600{ }^{\circ} \mathrm{C}$ therefore, doped ceria has been used as a potential electrolyte material instead of the YSZ for low temperature SOFCs(LT-SOFC), but doped ceria converts from $\mathrm{Ce}^{4+}$ to $\mathrm{Ce}^{3+}$ under reducing environment.

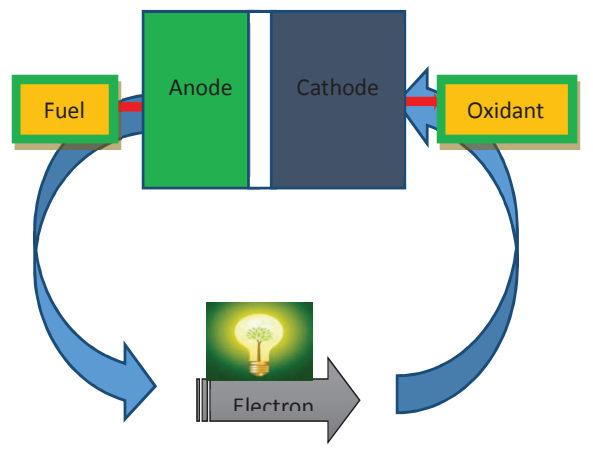

Figure 1: Fuel cell operating principle

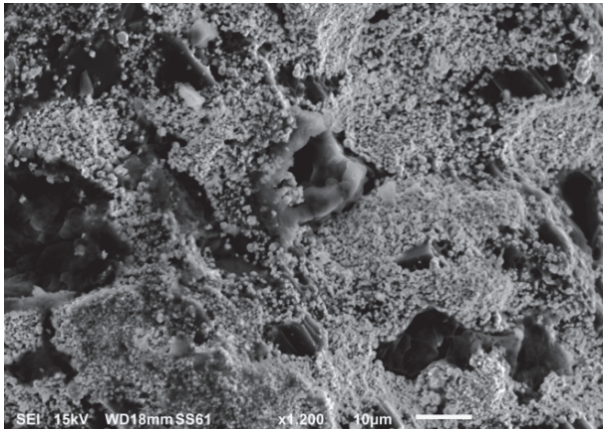

Figure 2: SEM micrograph of ceria carbonate electrolyte showing ceria and carbonate phases.

In this work, doped ceria oxide is mixed with sufficient amount of carbonate to make a composite which can be used as an electrolyte material for low temperature SOFCs (LTSOFC). Addition of the carbonate phase aids the ionic conductivity of the electrolyte by providing a super ionic pathway, acting as a liquid phase and reduces the electronic conductivity issues faced by doped ceria under reducing conditions. Figure 2 shows SEM micrograph of the ceria carbonate electrolyte. Thus addition of the carbonate lowers the temperature of operation and also aiding the economics of the process. The conductivities measured for these electrolytes are more than $0.21 \mathrm{~S} \mathrm{~cm}^{-1}$ at $600^{\circ} \mathrm{C}$, which is better than the previous studies done on ceria carbonate electrolytes [2].

Carbonate optimisation and cell testing has been carried out for these electrolyte. Physical and electrochemical characterisation has been done using XRD, SEM, TEM, EDX, TGA and potentiostat/galvanostat respectively.

\section{References}

1. B.H.C. Steele, Solid State Ionics 129 (2000) 95110.

2. R. Chockalingam, S. Jain, S. Basu, Integrated Ferroelectrics 116 (2010) 23-34. 